\title{
What influences consumers' intention to purchase organic personal care products? The role of social reassurance
}

\begin{abstract}
Green and organic markets have grown rapidly in recent times, thanks to the increasing global popularity of having a healthier lifestyle. Rising consumer awareness of the risks of synthetic chemicals for humans as well as the environment have boosted the demand for organic personal care products (PCPs). To better understand the micro-mechanisms guiding the organic PCPs buying process, this study builds on the social proof theory by examining the drivers leading this process in two different national contexts. Partial least squares structural equation modelling was used to conduct a multigroup analysis on a sample of 473 consumers ( $n=266$ from Spain, $n=207$ from Italy). Findings reveal the significant role of environmental value, product knowledge, convenience \& quality, and information adoption. Furthermore, the study introduces and validates the new construct 'social reassurance' explaining the psychological mechanisms leading the organic PCPs buying process.
\end{abstract}

\section{Keywords:}

Social proof theory; Social reassurance; Organic PCPs; Information adoption; Values; Quality; Purchase intention; PLS-SEM.

\section{Introduction}

The cosmetic industry has grown over the years and is one of the sectors holding relatively high potential for further growth and development. The rapid increase in demand for cosmetic products has fuelled global competition, motivating the industry to become more innovative and creative to gain a competitive advantage (Cosmetics Europe, 2020). Companies, to improve their income, are increasingly aligning their mission and vision with the rising consumer preference for a healthy lifestyle (Ghazali et al., 2017) they have begun to invest in organic personal care products (PCPs) to revitalise maturing cosmetics markets, such as the United States (US), France, Italy, or Spain, which are characterised by declining cosmetics sales and growth (Nosi et al., 2020). On the one hand, the PCPs global market size reached US\$ 15,500 million in 2019 and is supposed to cross US\$ 22,000 million in 2024 (Reuters, 2019); on the other, the Organic Trade Association reported that organic products sales in the US reached US\$ 47,000 million in 2016 (Hwang and Chung, 2020) and consumers' desire for safe, healthy, and clean products has been increasing worldwide particularly after the outbreak of COVID-19 (Organic Trade Association, 2020). Aligned with this, there has been a growing consensus amongst scholars on the significant role of consumers' concern for personal health as a predictor of positive attitude towards and the intention to purchase organic products (Hansen et al., 2018). In addition, a future market growth trend can also be predicted on the basis of the results of recent research on millennials' buying process of 
organic products (Molinillo et al., 2020). Social and health consciousness directly and positively influence younger consumers' intention to pay a premium price and their organic products' purchase frequency. The resulting effects on the sales volume and value in the coming years will be evident. Specifically for care products, Statista (2020) reported that global sales of organic PCPs will increase-from US\$ 34,500 million in 2018 to US\$ 54.5 million in ten years from now. Organic PCPs, just like all cosmetic products, can be classified as 'experience goods' because consumers usually learn about their quality and attributes during the pre-purchase and pre-consumption process (Nelson, 1970, 1974). Organic PCPs include skin/hair/oral care, deodorisers, and hygiene goods comprising natural ingredients without pesticides, fertilisers, or genetically modified organisms (Organic.org, 2016). As several studies have shown (Alaei et al., 2020; Huang et al., 2009; Rialti et al., 2018), the spread of the Internet and consequent social interactions enabling companies' and brands' touchpoints along consumers' journey have a significant effect on consumer search and purchase behaviour for experience goods. This clearly shows the need to better investigate the underlying micro-mechanisms explaining the PCPs buying process.

Despite the multiplicity of social interactions, the most commonly adopted form is online ratings and reviews, considered a traditional type of electronic-word-of-mouth (eWOM) communication. Given its influence on consumers' perceptions and behavioural attitudes and intentions (Filieri, 2015; Dubois et al., 2016, Consiglio et al., 2018), researchers have increasingly focused on eWOM, traditionally defined as 'any statement made by potential, actual, or former customers about a product or company, which is made available to a multitude of people and institutions via the Internet' (Hennig-Thurau et al., 2004, p.13). Through eWOM, individuals tend to learn by observing others within their social networks (Im et al., 2007). Cialdini (1993) suggested that keeping within one's network similar others using a product provides a sort of 'social proof' that the product is worthwhile and desirable - consumers tend to decide their most appropriate behaviour in a determined situation by examining others', especially 'significant' and 'important' others (Cialdini, 1993). In other words, consumers validate the appropriateness and acceptability of their behavioural decision-making processes through social comparison with their important others (Festinger, 1954; Zollo, 2020). Consequently, individuals are more willing to decide and act like their friends and peers have done. For instance, social proof as a socio-anthropological model has been proved to determine several actions such as returning a lost wallet (Hornstein et al., 1968), littering in public places (Cialdini et al., 1990), donating to charities (Reingen, 1982), or buying specific products (De Langhe et al., 2015).

Considering the cosmetic industry recent growth, demand and supply of organic PCPs assume a key role in the modern market scenario, thus requiring a closer investigation by retailing and consumer services scholars (Ghazali et al., 2017; Prakash et al., 2019; Yadav, 2016). Specifically, as recently highlighted by Sadiq et al. (2020), the market of organic PCPs still being in its nascent phase calls for more studies to better investigate the socio-psychological predictors leading consumers to purchase such products. In particular, the micro-mechanisms guiding the organic PCPs buying process are still unclear and need further research. Thus, by applying the social proof theory (Cialdini, 1993), the aim of this study was to investigate the mechanisms leading consumers of organic PCPs to read online reviews, while considering how such reviews 
influence the intention to purchase these products - in so doing, it addresses the recent calls for more research on how social norms (Cialdini et al., 1990) reduce consumption barriers and foster consumers' attitude towards and their intention to purchase organic PCPs (Kim and Seock, 2019; Sadiq et al., 2020). It is therefore crucial for the cosmetic industry to understand how this intention could differ across countries due to different levels of consumers' awareness and appreciation (Aday and Yener, 2014; Yang et al., 2017). To fill this gap, this study empirically investigated the psychological mechanisms leading the organic PCPs buying process by applying the socio-anthropological social proof theory in two maturing and similar European cosmetics markets-Italy and Spainthat have not yet received significant attention research-wise. However, the purpose was not to scrutinise the buying process using a sociological lens, but to study the main organic PCPs drivers and social reassurance elements across the two market contexts.

In the second section, a review of the existing research is presented and an integrated and holistic conceptual model proposed. Then, the research methodology to empirically test this model across the two national contexts is explained. Next, the results are discussed, providing theoretical and practical implications. Finally, the limitations are reported along with proposals for future research.

\section{Theoretical background and research model development}

Based on the organic products literature (e.g. Ghazali et al., 2017; Hwang and Chung, 2020; Prakash et al., 2019; Sadiq et al., 2020; Yadav, 2016), PCPs buying process is determined by different drivers mainly referring to consumers' values and knowledge about such products. From the former, environmental value is related to concerns about the possible harmful impact of chemicals present in traditional PCPs on the environment (Boxall et al., 2012). Aligned with this, safety value is defined as the degree to which consumers perceive the consumption of organic products as harmless because these are free of chemicals (Bauer et al., 2013). Similarly, health value involves protection and enhancement of health vis-à-vis organic PCPs consumption (Xie et al., 2015). Product knowledge, on the other hand, is considered as a consumer's personal knowledge and self-perception of how much he/she knows about organic PCPs (Vermeir and Verbeke, 2008). Ghazali et al. (2017) showed that some of these drivers positively affect consumers' attitude towards and their intention to purchase organic PCPs - specifically, environmental value was the highest correlated variable with purchase intention, and product knowledge had the most decisive impact on attitude. Consistent with this, Yadav (2016) found that consumers' environmental concerns are significantly related to both attitude towards and the intention to purchase organic food products.

Based on the social proof theory (Cialdini, 1993), our aim was to focus on the effect of social reassurance to further and better explain the underlying mechanisms explaining these relationships. Accordingly, social reassurance is considered as an individual's tendency to compare his/her evaluation with one of the others (Kim et al., 2011). According to Amblee and Bui's (2001) investigation of social proof and eWOM in online shopping, the former is established when 'consumers rely on the collaboratively shared information and experiences of others to infer a course of action' (p.91). Social proof 
might thus be interpreted as an important 'source of signal' from reliable and trustworthy online sources such as reviews, ratings, and eWOM (Filieri, 2015; Dubois et al., 2016; Consiglio et al., 2018). Applying Cialdini's (1993) seminal definition to our context, consumers of organic PCPs who believe their similar/significant others possess knowledge and engage in appropriate behaviour concerning those products' purchase will 'view a behaviour as correct in a given situation to the degree that they see others performing it' (p.100). Applying social reassurance to our context, the relationship between consumers' pro-environmental values and product knowledge can be unpacked through their perceptions of other consumers' reviews, comments, feedback, and more in general eWOM (Filieri, 2015) about the same product. Hence, the alignment between one's own values, knowledge, and evaluation of others' opinions and behaviours results in a 'reassuring' factor incentivising the consumer to purchase the product (HennigThurau and Walsh, 2003; Hennig-Thurau et al., 2004). Thus, the higher the proenvironmental values of a consumer and his/her understanding, familiarity, and knowledge of organic PCPs (Bauer et al., 2013; Park et al., 1992), the more he/she will look for reviews, comments, and social reassurance from other similar organic PCPs consumers (see also Ghazali et al., 2017). Based on the above, we hypothesise:

H1: Environmental value significantly influences social reassurance $(\mathrm{EV} \rightarrow \mathrm{SR})$.

H2: Product knowledge significantly influences social reassurance $(\mathrm{PK} \Rightarrow \mathrm{SR})$.

Supported by the literature on the motivations to read online reviews (e.g. Kim et al., 2011), social reassurance is expected to influence consumers' information adoption through the convenience \& quality perception. Information adoption refers to people purposefully seeking recommendation for a product and then using such information (Filieri, 2015). Thus, information adoption reflects the positive effect of others' reviews and recommendation on consumers' purchase experience. In this way, consumers significantly benefit from social reassurance in terms of effectiveness, ease, and convenience of the purchase experience, especially in online communities (Watts and Zhang, 2008) and on social media websites (Erkan and Evans, 2016). With respect to the present study, information adoption reveals the informational effect of eWOM. At the same time, convenience \& quality refers to the ease in use of information searched online (Goldsmith and Horowitz, 2006), and is strictly related to trust and image (MartínConsuegra et al., 2018). Specifically, convenience \& quality explains the main reason, rationale, and mechanism behind why consumers look for others' online reviews and comments in terms of a faster, easier, cheaper, quicker, and convenient purchase decision and experience (Hennig-Thurau and Walsh, 2003). Thus, looking for other consumers' reviews, feedback, opinions, and comments stems from the need to be 'reassured' in a fast, convenient, and easy way, especially in online environments such as the web (Kim et al., 2011). This is particularly true when consumers have to compare and choose from different alternatives online. Building on this, we hypothesised convenience \& quality to be the mediating variable explaining the underlying relationship between consumers' need of social reassurance and their propensity for information adoption. In other words, 'socially reassured' consumers are more likely to effectively exploit others' reviews and recommendations for their decision convenience \& quality, and also benefit more from 
adopting such online information in terms of product purchase experience (see Filieri, 2015; Hennig-Thurau and Walsh, 2003; Kim et al., 2011). Accordingly, we hypothesise:

H3: Social reassurance significantly influences convenience \& quality (SR $\Rightarrow \mathrm{CQ})$.

H4: Social reassurance significantly influences information adoption ( $\mathrm{SR} \rightarrow \mathrm{IA})$.

H5: Convenience \& quality significantly influences information adoption (CQ $\Rightarrow \mathrm{IA})$.

Based on the Theory of Planned Behaviour (Ajzen and Fishbein, 1980), information adoption has a positive influence on consumers' intention to purchase organic PCPs. The vast majority of this information derives from conventional practices of eWOM communication (Rialti et al., 2017). Through the Internet and social media (Zollo et al., 2020), consumers receive, either intentionally or accidentally, a substantial volume of eWOM material. Preceding research has confirmed the influence of eWOM communication on consumer purchase intention (Erkjan and Evans, 2016; See-to and Ho, 2014; Wang et al., 2012); yet, the level of impact of eWOM material posted on social media and reviews on consumer purchase intention fluctuates (Yang, 2012). The stronger the information adoption, the greater the likelihood of individuals using recommendations or reviews as evidence of truth. The acceptance of information from friends and peers encourages individuals to purchase organic PCPs. Indeed, following the seminal work of Ajzen and Fishbein (1980), the more favourable the individual's attitude towards a particular behaviour, the greater the likelihood of he/she engaging in that same behaviour. Within our scope of analysis, the consumer attitude to assess and evaluate others' eWOM (Filieri, 2015) about a product - by adopting available online information-may be interpreted as the key driver of the intention to buy the product. Hence, we hypothesise:

H6: Information adoption significantly influences consumers' intention to purchase organic PCPs $(\mathrm{IA} \rightarrow \mathrm{INT})$.

We also investigated to what extent the relationships shown in Figure 1 differ according to the national context. In 2018, according to Cosmetics Europe (2020), Europe was the largest cosmetics market in the world, valued at $€ 78.6$ billion-Germany is a major market for cosmetic products ( $€ 13.8$ billion in 2018$)$, followed by France $(€ 11.4$ billion), the United Kingdom (UK) (€10.9 billion), Italy (€10.1 billion), and Spain ( $€ 7$ billion). Although the scope of this study did not extend to examining differences in cultural factors affecting the intention to purchase organic PCPs, it nevertheless compared two similar national structural (industry, macro-, and socioeconomic factors) and cultural contexts to improve the results' generalisability because there are more similarities than dissimilarities (Pantano et al., 2017). While Spain and Italy GDP per capita for 2019 were US\$ 31,060 and US\$ 34,350, respectively, the average hourly wages in Spain (US\$ 11.4) and Italy (US\$ 11.6) were similar (The World Bank, 2020). Thus, this study is built upon Koopman et al.'s (1999) distinction of European clusters concerning cultural values, by considering that Italy and Spain, instead of Germany, France, or the UK, might show similar approaches towards social reassurance and information adoption regarding organic PCPs for supporting their purchase. Socioeconomic contribution of Spain and Italy's cosmetic industries are presented from different aspects. First, cosmetics expenditure per capita in Spain $(€ 149)$ and Italy $(€ 167)$ is similar and significantly 
increasing every year (Euromonitor International, 2020). With regard to the value of cosmetic export from Europe by export country (Italy $€ 2,023$ billion and Spain $€ 1,852$ billion), both contexts account for similar numbers. Additionally, data from Cosmetics Europe (2020) for 2018 indicates that more than 138,000 people are employed directly in the manufacture of cosmetic products - the number of workers in Spain $(14,410)$ and Italy $(18,330)$ is quite close. In relation to the enterprises in the cosmetic value chain, Eurostat (2020) reported that there were approximately 23,000 companies involved in the wholesale of cosmetics in Europe for 2015, the majority located in Italy (17\%), Spain $(15 \%)$, and France (10\%). However, there is a difference in the number of organisations involved in the retail sale of cosmetics (specialised stores) by country (Spain: 6,300, Italy: 12,350). Furthermore, there are at least 77 innovation facilities in Europe researching into cosmetics, with more than 50\% located in Spain. Finally, using two countries with similar cultural backgrounds can build a more convincing argument about the intention to purchase organic PCPs than conducting a study in a single country or culturally different ones (Roy et al., 2020). Since there are only slight differences in the dimensions of Hofstede between Italy and Spain (Hofstede Insights, 2020), it is expected invariance across two groups:

H7: There are no significant differences in the intention to purchase organic PCPs between Spanish and Italian consumers.

Specifically, this study proposes that there are no significant differences in the relationships between $(\mathrm{H} 7 \mathrm{a})$ environmental value and social reassurance, $(\mathrm{H} 7 \mathrm{~b})$ product knowledge and social reassurance, $(H 7 c)$ social reassurance and convenience \& quality, $(H 7 d)$ social reassurance and information adoption, $(H 7 e)$ convenience \& quality and information adoption, and (H7f) information adoption and intention to purchase organic PCPs amongst Spanish and Italian consumers. Based on the above, Figure 1 summarises the hypotheses of the proposed conceptual model.

Insert Figure 1 here.

\section{Methodology}

\subsection{Questionnaire development and administration}

To test the proposed conceptual model (Figure 1), a survey-based approach (Rea and Parker, 2014) was employed to assess the hypothesised relationships empirically. This study builds upon the Hofstede-based approach. Spain and Italy were selected considering their cultural similarities in accordance with some cultural dimensions (Hofstede Insights, 2020). Specifically, the two countries present strong similarities in cultural dimensions such as uncertainty avoidance, power distance, and indulgence. Additionally, uncertainty avoidance value was a determining factor in the decision 
because Hofstede (2011) and Litvin (2019) have suggested that it is the most significant dimension in international environments.

A pretest was performed to avoid complex and lengthy statements, and the questions were kept simple, concise, and specific to avoid non-response bias (Rogelber and Stanton, 2007). Specifically, the pretest aimed at ensuring careful design, completion ease, length appropriateness, and items' clarity. After the pretest, no changes were made to the questionnaire, which was considered appropriate for data collection. Additionally, to deal with social desirability bias and common method variance (Podsakoff et al., 2003), the questionnaire's cover letter stressed on anonymity, confidentiality, and independence of the respondents. Moreover, it was emphasised that participation was voluntary, no compensation would be provided, and there were no right or wrong answers. Finally, the survey questions measuring independent variables were separated (i.e., the social reassurance antecedents) from the items measuring the dependent variables (i.e., purchase intention) (Podsakoff et al., 2012). To further control non-response bias, wave analysis was conducted to compare early respondents with late ones. Particularly, we conducted a T-test to compare respondents' answers according to demographic variables of the survey, such as age, education level, gender, and the key variables (i.e., social reassurance and purchase intention). The T-test showed no significant statistical mean differences amongst the variables, thus alleviating non-response bias concerns (Rogelber and Stanton, 2007).

Data was collected via an online survey from January to March 2020. Potential respondents in both countries were recruited through a national consumer panel. The final sample comprised 473 valid respondents - the Italy survey was conducted in Italian, yielding 207 usable responses, and the Spain survey in Spanish, giving 266 completed and usable questionnaires (see Table 1). In the Italian sample, $81 \%$ respondents were female; most were in the age groups 36-50 (41\%) and 51-65 (36\%); and a majority had a high-school diploma (52\%) or a bachelor's degree (38\%). In the Spanish sample, $79 \%$ respondents were female; most were in the age group 18-35 (70\%), followed by 51-65 $(18 \%)$; and a high number of respondents had a high-school diploma $(35 \%)$ or a bachelor's degree $(50 \%)$.

Insert Table 1 here.

To operationalise the constructs, measures adapted in previous studies were used (see Table 2). Thus, environmental value was captured through the four-item scale by Lea and Worsley (2005), recently applied by Bauer et al. (2013) and Ghazali et al. (2017). Product knowledge was captured through the five-item scale validated by Park et al. (1992) and recently used by Ghazali et al. (2017). Social reassurance was measured using a six-item instrument, combining four sub-dimensions: (1) determination of social position, (2) belonging to a virtual community, (3) learning what products are new in the market, and (4) learning how a product is to be consumed. The mediating variable of the proposed model is convenience \& quality, which is a seven-item scale by Hennig-Thurau and Walsh (2003) and Kim et al. (2011). The last two outcome variables are information adoption, a four-item instrument validated by Filieri (2015), and intention to purchase 
organic PCPs, a five-item scale by Ghazali et al. (2017). To measure the variables included in the proposed model, multi-item scales validated by previous studies were used, with a Likert-type scale ranging from 1 to 7.

Insert Table 2 here.

\subsection{Statistical procedures}

To assess the model, structural equation techniques based on variance were used, specifically, partial least squares structural equation modelling (PLS-SEM). This technique estimates partial model structures by combining the analysis of main components with ordinary least squares regressions (Hair et al., 2019). The main reasons justifying the choice of PLS-SEM include: (a) the proposed model uses composites (Henseler, 2017); (b) the path model contains formatively measured constructs, such as social reassurance (Hair et al., 2019); and (c) nonparametric SEM techniques are suitable to perform a multigroup analysis (Rasoolimanesh et al., 2017). To estimate the proposed model, Smart PLS 3.2.9 was utilised. The PLS-SEM literature marks the following: (1) to perform measurement model evaluation, (2) to evaluate the structural model, (3) to assess measurement invariance using the MICOM procedure, and (4) to evaluate the multigroup analysis (Hair et al., 2019; Henseler et al., 2016).

The measurement model for the Spanish and Italian consumers was evaluated thus. First, reliability of measurement scales was studied for environmental value, product knowledge, convenience \& quality, information adoption, and intention to purchase organic PCPs (all the dimensions were estimated in Mode A). The items' individual reliability was evaluated through the loadings of the indicators in both groups.

In general, a high level of internal consistency was observed in both groups (see Table 3). In this case, all the loadings for the respondents were greater than 0.708 . The individual reliability of each construct was verified using three indicators: Cronbach's $\alpha$ (CA), Dijkstra-Henseler's rho $\left(\rho_{A}\right)$ and Composite Reliability (CR) (Hair et al., 2019).

Insert Table 3 here.

To assess convergent validity, Average Variance Extracted (AVE) was used, which was greater than 0.5 in all cases (Fornell and Larcker, 1981). In addition, the Fornell-Larcker criterion indicated a satisfactory level of discriminant validity for both groups (see Table 4). This result is supported by the HTMT evaluation, which determines the ratio between heterotrait-monotrait correlations, with discriminant validity when values are lower than 0.90 (Henseler et al., 2015).

To complete the evaluation of the measurement model, social security was assessed (Mode B; see Table 5). Thus, the Variance Inflation Factor (VIF) was assessed, indicating that there was no collinearity problem because the VIF levels were lower than 
the established limit. Then, the significance of the weights was evaluated. Since there was no collinearity problem and the loads were greater than 0.5 , no indicators were eliminated (Hair et al., 2019). Only SR1 was less than 0.5 for the Spanish consumers; however, this indicator was significant at $99.9 \%$ for the Italian consumers. Once the validity and reliability of the measurement model were verified, the proposed structural model was examined using the bootstrapping resampling procedure.

Insert Table 4 here.

Insert Table 5 here.

\section{Results}

The explanatory capacity of the global structural model was assessed using $\mathrm{R}^{2}$ (Hair et al., 2019) - the $\mathrm{R}^{2}$-values were 0.445 for social reassurance, 0.618 for convenience \& quality, 0.735 for information adoption, and 0.297 for intention to purchase organic PCPs. Table 6 also shows the structural model evaluation for the respondents. Subsequently, the path coefficients and their significance levels were examined to assess the proposed structural relationships (Hair et al., 2019) (see Table 7). Environmental value and product knowledge appeared to be significant and positive, at 99.9\% in social reassurance. Thus, $H 1$ and $H 2$ are supported, as product knowledge was found to be the construct with the greatest importance in social reassurance $(\beta=0.251$ and 0.454 , respectively). As proposed in $H 3$, social reassurance was positively associated with convenience \& quality, being the strongest relationship in the model $(\beta=0.786)$. Similarly, social reassurance and convenience \& quality were found to have a significant influence on information adoption, confirming $H 4$ and $H 5$ as well $(\beta=0.366$ and 0.539 , respectively). Finally, information adoption was found to have a significant influence on intention to purchase organic PCPs, thus confirming H6 $(\beta=0.545)$.

Insert Table 6 here.

Insert Table 7 here.

Next, a multigroup analysis was carried out to evaluate $H 7$. The aim was to confirm the moderating potential of each national context (Spain and Italy) for intention to purchase organic PCPs in the proposed relationships. However, the analysis of the MICOM procedure is crucial before conducting multigroup analysis to corroborate that the existing differences are not due to the measurement model, but due to differences in 
the structural model; it comprises three steps: (Step 1) configuration invariance, (Step 2) compositional invariance, (Step 3a and $3 b$ ) the equality of composite mean values and variances (Henseler et al., 2016) (see Table 8). In this study, the equality of the composites' mean values and variances was not verified; hence, the measurement invariance was partial.

Insert Table 8 here.

Taking the measurement invariance into consideration, the multigroup analysis indicated that the differences in p-values were significant just for $H 7 f$, thus supporting $H 7 a, H 7 b, H 7 c, H 7 d$, and $H 7 e$. In this way, the result indicated that there were no significant differences between the Spanish and Italian consumers' intention to purchase organic PCPs, only in the relationship between information adoption and intention to purchase organic PCPs amongst both groups (see Table 9).

Insert Table 9 here.

Finally, as an extension of the findings, the Importance-Performance Map Analysis (IPMA) was also carried out using intention to purchase organic PCPs as the principal construct. IPMA verifies the total effects, indicating its importance in forming a construct, with their average latent variable scores suggesting their performance (Ringle and Sarstedt, 2016). Hence, IPMA for the Spanish consumers (see Figure 2) showed information adoption as the variable that most affects the intention to purchase organic PCPs. One point increase in the performance of purchase intention determined a total effect of 0.595 . Importance of product knowledge was low because of its low performance over intention to purchase organic PCPs. For the Italian consumers (Figure 2), IPMA showed that the importance of these variables was lower than that for the Spanish consumers vis-à-vis the intention to purchase organic PCPs; yet, the performance was higher than for the Spanish consumers.

Insert Figure 2 here.

\section{Discussion}

By using a socio-anthropological approach, this study introduces a new construct (social reassurance) explaining the psychological mechanisms leading the organic PCPs buying process. According to this new approach, the eWOM effects on the process, traditionally studied by marketing literature, have been interpreted differently. Employing the social proof theory, social reassurance has proven to be effective in understanding consumer attitudes towards organic PCPs in a two-country comparison. In particular, product knowledge is a valuable antecedent of social reassurance because, in the case of 
experience goods like organic PCPs, consumers need to be well informed and perfectly aware of the product characteristics as quality is important to them. This is the main reason that motivates them to read and seek out other consumers' opinions. Furthermore, environmental value, generally used in the literature to explain consumer behaviour in the case of organic products (Ghazali et al., 2017), is significantly related to social reassurance. Organic products are considered to be environmentally safer compared with their traditional counterparts. These results are in harmony with those of preceding studies (e.g. Bauer et al., 2013; Han and Chung, 2014; Kim and Chung, 2011; Zollo et al., 2018), which have supported the idea that consumers consider the environmental benefits of ecofriendly products when making purchase decisions. Going deeper into the analysis, the results show how convenience \& quality drives consumers' information adoption - this is the strongest relationship in the proposed model. Similarly, the relationship between social reassurance and information adoption is also established. This can have valuable marketing implications.

The proposed model has a strong predictive value of information adoption (73.5\%) and low predictive value of intention to purchase organic PCPs (29.7\%). Focus on product knowledge, environmental value, and social reassurance that enforces quality and convenience beliefs leads to information that has a probability of being adopted, subsequently developing the purchase intention. However, while these results are consistent with those of previous studies (i.e., Prakash et al., 2019) that found low-weight relationships vis-à-vis the intention to purchase eco-friendly products, other researches (i.e., Ghazali et al., 2017) have found that the prediction of intention to purchase PCPs is higher if hedonic values are included. Thus, these authors have suggested that hedonic values have a strong influence on the attitude to use PCPs and help to increase the intention to use them. Additionally, Prakash and Pathak (2017) found higher values as their study focused on young consumers, who are more environmentally aware. The possible reasons for the differences between previous studies include research targets, regions, and time differences (Ghazali et al., 2017). This study employed the PLS-SEM methodology to perform a multigroup analysis, which determined significant relationships amongst Spanish and Italian consumers. The findings of this analysis show that two countries with similar cultural backgrounds demonstrate identical behaviour in the intention to purchase organic PCPs - the relationship between information adoption and intention to purchase organic PCPs was the only one with significant differences between Spanish and Italian consumers; thus, information adoption was more relevant to the intention to purchase organic PCPs for the Spanish consumers than for their Italian counterparts. Consequently, the proposed model explains only $7.9 \%$ of intention to purchase organic PCPs for the Italian consumers, and 27\% for the Spanish ones.

Last but not the least, this study makes an important contribution to the literature by conducting IPMA. Due to the importance of social reassurance and antecedent variables, convenience \& quality, and information adoption for the purchase of organic PCPs in this study, it is essential to analyse the contribution of these variables in increasing the intention to purchase organic PCPs. The IPMA findings show that information adoption was the most important variable in defining the intention to purchase organic PCPs for both groups of consumers. In addition, IPMA shows that the importance of these variables for the intention to purchase organic PCPs was lower for 
the Italian consumers than for their Spanish counterparts, but the performance was higher for the Italian consumers than the other group.

\subsection{Implications}

It is first recommended that e-commerce platform operators continue to encourage their community of shoppers to publish online reviews, as these are linked to the intention to use organic products - to achieve this, managers could customise the review request by email, grant loyalty points for a review, or even start a small online campaign giving all loyal customers discount codes in exchange for a review. In other words, the tools for collecting reviews are many, as are the ways these can be used as 'advertisements' outside the site in newsletters, Facebook and Instagram posts, and so on. Second, the content of social reassurance should primarily focus on product knowledge and information. Third, to encourage information adoption, managers must use reviews considering consumers' reason for reading them: having a 'shortcut' that convinces one to purchase the product. This means that the sample sees the reviews as a 'shortcut' within an incredibly difficult procedure, such as the purchase of experience goods wherein the consumer evaluates all the information available on the site and seeks a reliable guarantee for everything he/she does not have the opportunity to assess. The complexity of the buying process is dictated by the attention the consumer of natural cosmetics pays in choosing the product. Thus, an informed consumer leaves nothing to chance and reports on the product content, specifically, the active ingredients used and their efficacy, the company and its certifications, and so on. In this context, the social proofing effect of the review can play a crucial role when the time for product selection is less, a well-known trend for all online businesses. In this sense, giving reviews the right visibility can make a difference and lead the reader to one choice over another. The implications of 'convenience $=$ shortcut' should be translated into strategic placement of reviews on the website. In other words, managers should position them appropriately to provide easy and wide visibility to consumers. In addition, managers should be more attentive towards the adoption of information about organic PCPs by Italian consumers - they could motivate these consumers to read reviews that will provide them with useful information for the organic PCPs buying process. In conclusion, marketing managers can benefit from the results of this study by taking into consideration all the advantages the social proof theory can produce in managing reviews, as indicated here.

\subsection{Limitations and future research}

This study collected data from consumers in Spain and Italy. Consequently, the first limitation is the sample size. Even though this is a two-country comparison between the Spanish and Italian markets, the inclusion of more attractive markets for organic PCPs, such as Germany, France, and the UK, would be a value addition. Beyond that, Asian and American countries, driven by different cultures and consumer behaviour, are also excellent options to compare the impact of social reassurance and information adoption on the intention to purchase organic PCPs. Examining the conceptual model in different settings would enhance external validity, and indicate if nationwide market differences impact the relationships between social reassurance, information adoption, and purchase intention. The second limitation is that this study has a cross-sectional design - it is based on data collected from respondents who already know and/or consume 
organic products. Organic PCPs are going through a developmental phase, with a considerable number of new brands and category products coming out every year. The new launches could be a refreshing option for consumers, who have had a range of only traditional cosmetic products to choose from, potentially modifying the meaning of organic PCPs. Thus, future research should consider longitudinal designs or fieldwork to determine the relationships proposed in this study. In addition, this study could consider other variables, such as hedonic values; thus, the explained variance of intention to purchase organic PCPs could be improved. According to Hair et al. (2019), the greater the number of predictor constructs, the higher the $\mathrm{R}^{2}$. Finally, another avenue for this study is looking at the same data through a new lens. Apart from PLS-SEM, other methods to analyse possible groupings (Hair et al., 2018), or test more elaborate models to understand the conceptualised relationships can be employed comprehensively. Nevertheless, this study is innovative in terms of identifying the link between social reassurance and the intention to purchase organic PCPs across two global markets.

\section{References}

Aday, M. S., \& Yener, U. (2014). Understanding the buying behaviour of young consumers regarding packaging attributes and labels. International Journal of Consumer Studies, 38(4), 385-393.

Ajzen, I. (1991). The theory of planned behavior. Organisational behavior and human decision processes, 50(2), 179-211.

Alaei, A.M., Taleizadeh, A.A., \& Rabbani, M. (2020). Marketplace, reseller, or web-store channel: The impact of return policy and cross-channel spillover from marketplace to web-store. Journal of Retailing and Consumer Services. DOI: 10.1016/j.jretconser.2020.102271.

Amblee, N., \& Bui, T. (2011). Harnessing the influence of social proof in online shopping: The effect of electronic word of mouth on sales of digital microproducts. International Journal of Electronic Commerce, 16(2), 91-114.

Arvola, A., Vassallo, M., Dean, M., Lampila, P., Saba, A., Lähteenmäki, L., \& Shepherd, R. (2008). Predicting intentions to purchase organic food: The role of affective and moral attitudes in the Theory of Planned Behaviour. Appetite, 50(2-3), 443-454.

Bagozzi, R.P., and Yi, Y. (1988). On the evaluation of structural equation models. Journal of the Academy of Marketing Science, 16(1), 74-94.

Baron, R. M., \& Kenny, D. A. (1986). The moderator-mediator variable distinction in social psychological research: Conceptual, strategic, and statistical considerations. Journal of Personality and Social Psychology, 51(6), 1173-1182.

Bauer, H. H., Heinrich, D., \& Schäfer, D. B. (2013). The effects of organic labels on global, local, and private brands: more hype than substance? Journal of Business Research, 66(8), 1035-1043.

Bentler, P.M. (1990). Comparative fit indexes in structural models. Psychological Bulletin, 107(2), 238-246. 
Boxall, A. B., Rudd, M. A., Brooks, B. W., Caldwell, D. J., Choi, K., Hickmann, S., ... \& Ankley, G. T. (2012). Pharmaceuticals and personal care products in the environment: what are the big questions? Environmental Health Perspectives, 120(9), 1221-1229.

Bredahl, L. (2001). Determinants of consumer attitudes and purchase intentions with regard to genetically modified food-results of a cross-national survey. Journal of Consumer Policy, 24(1), 23-61.

Cialdini, R. B. (1993). Influence: The psychology of persuasion. New York: Morrow.

Cialdini, R. B., Reno, R. R., \& Kallgren, C. A. (1990). A focus theory of normative conduct: recycling the concept of norms to reduce littering in public places. Journal of Personality and Social Psychology, 58(6), 1015.

Consiglio, I., De Angelis, M., \& Costabile, M. (2018). The Effect of Social Density on Word of Mouth. Journal of Consumer Research, 45(3), 511-528.

Cosmetics Europe (2020). CE Statistics 2019. Available at: https://cosmeticseurope.eu/library/ (Accessed 24 July 2020).

Davidow, M. (2003). Organisational responses to customer complaints: What works and what doesn't. Journal of Service Research, 5(3), 225-250.

De Langhe, B., Fernbach, P. M., \& Lichtenstein, D. R. (2015). Navigating by the stars: Investigating the actual and perceived validity of online user ratings. Journal of Consumer Research, 42(6), 817-833.

Dubois, D., Bonezzi, A., \& De Angelis, M. (2016). Sharing with friends versus strangers: How interpersonal closeness influences word-of-mouth valence. Journal of Marketing Research, 53(5), 712-727.

Erkan, I. \& Evans, C. (2016). The influence of eWOM in social media on consumers' purchase intentions: An extended approach to information adoption. Computers in Human Behavior, 61, 47-55.

Euromonitor International (2020). Beauty and Personal Care Dashboard. Available at: https://www.portal.euromonitor.com/portal/dashboard/index (Accessed 24 July 2020).

Eurostat (2020). Annual enterprise statistics. Available at: http://ec.europa.eu/eurostat/data/database (Accessed 24 July 2020).

Festinger, L. (1954). A theory of social comparison processes. Human Relations, 7(2), 117-140.

Filieri, R. (2015). What makes online reviews helpful? A diagnosticity-adoption framework to explain informational and normative influences in e-WOM. Journal of Business Research, 68(6), 1261-1270.

Fornell, C. \& Larcker, D.F. (1981). Evaluating structural equation models with unobservable variables and measurement error. Journal of Marketing Research, $18(1), 39-50$. 
Ghazali, E., Soon, P. C., Mutum, D. S., \& Nguyen, B. (2017). Health and cosmetics: Investigating consumers' values for buying organic personal care products. Journal of Retailing and Consumer Services, 39, 154-163.

Goldsmith, R. E., \& Horowitz, D. (2006). Measuring motivations for online opinion seeking. Journal of Interactive Advertising, 6(2), 2-14.

Hair, J. F., Black, W. C., Babin, B. J., \& Anderson, R. E. (2018). Multivariate Data Analysis. Cengage, London.

Hair, J.F., Risher, J.J., Sarstedt, M. \& Ringle, C.M. (2019), "When to use and how to report the results of PLS-SEM. European Business Review, 31(1), 2-24.

Hennig-Thurau, T. \& Walsh, G. (2003). Electronic word-of-mouth: Motives for and consequences of reading customer articulations on the Internet. International Journal of Electronic Commerce, 8(2), 51-74.

Hennig-Thurau, T., Gwinner, K. P., Walsh, G., \& Gremler, D. D. (2004). Electronic word-of-mouth via consumer-opinion platforms: what motivates consumers to articulate themselves on the Internet? Journal of Interactive Marketing, 18(1), 3852.

Henseler, J. (2017). Bridging design and behavioral research with variance-based structural equation modelling. Journal of Advertising, 46(1),178-192.

Henseler, J. Ringle, C.M., and Sarstedt, M. (2015). A new criterion for assessing discriminant validity in variance-based structural equation modelling. Journal of the Academy of Marketing Science, 43(1), 115-135.

Henseler, J., Ringle, C.M., \& Sarstedt, M. (2016). Testing measurement invariance of composites using partial least squares. International Marketing Review, 33(3), 405431.

Hornstein, H. A., Fisch, E., \& Holmes, M. (1968). Influence of a model's feeling about his behaviour and his relevance as a comparison other on observers' helping behaviour. Journal of Personality and Social Psychology, 10(3), 222.

Hofstede, G. (2011). Dimensionalizing cultures: The Hofstede model in context. Online Readings in Psychology and Culture, 2(1), 8.

Hofstede Insights (2020). Country Comparison. Available at: https://www.hofstedeinsights.com/country-comparison/italy,spain/ (Accessed 24 July 2020).

Hu, L.T. \& Bentler, P.M. (1999). Cutoff criteria for fit indexes in covariance structure analysis: conventional criteria versus new alternatives. Structural Equation Modeling: A Multidisciplinary Journal, 6(1), 1-55.

Huang, P., Lurie, N. H., \& Mitra, S. (2009). Searching for experience on the web: an empirical examination of consumer behaviour for search and experience goods. Journal of Marketing, 73(2), 55-69. 
Hwang, J., \& Chung, J. E. (2019). What drives consumers to certain retailers for organic food purchase: The role of fit for consumers' retail store preference. Journal of Retailing and Consumer Services, 47, 293-306.

Im, S., Mason, C. H., \& Houston, M. B. (2007). Does innate consumer innovativeness relate to new product/service adoption behaviour? The intervening role of social learning via vicarious innovativeness. Journal of the Academy of Marketing Science, 35(1), 63-75.

Kim, E.E.K., Mattila, A.S., \& Baloglu, S. (2011). Effects of gender and expertise on consumers' motivation to read online hotel reviews. Cornell Hospitality Quarterly, 52(4), 399-406.

Kim, S.H., \& Seock, Y.K. (2019). The roles of values and social norm on personal norms and pro-environmentally friendly apparel product purchasing behavior: The mediating role of personal norms. Journal of Retailing and Consumer Services, 51, 83-90.

Koopman, P.L., Den Hartog, D.N., Konrad, E., \& Al, E. (1999). National culture and leadership profiles in Europe: some results from the GLOBE study. The European Journal of Work and Organizational Psychology, 8(4), 503-520.

Lea, E., \& Worsley, T. (2005). Australians' organic food beliefs, demographics and values. British Food Journal, 107(11), 855-869.

Litvin, S. W. (2019). Hofstede, cultural differences, and TripAdvisor hotel reviews. International Journal of Tourism Research, 21(5), 712-717.

Martín-Consuegra, D., Faraoni, M., Díaz, E., \& Ranfagni, S. (2018). Exploring relationships among brand credibility, purchase intention and social media for fashion brands: A conditional mediation model. Journal of Global Fashion Marketing, 9(3), 237-251.

Molinillo, S., Vidal-Branco, M., \&amp; Japutra, A. (2020). Understanding the drivers of organic foods purchasing of millennials: Evidence from Brazil and Spain. Journal of Retailing and Consumer Services, 52. DOI: 10.1016/j.jretconser.2019.101926.

Nelson, P. (1970). Information and consumer behaviour. Journal of Political Economy, 78(2), 311-329.

Nelson, P. (1974). Advertising as information. Journal of Political Economy, 82(4), 729754.

Nosi, C., Zollo, L., Rialti, R., \& Ciappei, C. (2020). Sustainable consumption in organic food buying behavior: the case of quinoa. British Food Journal, 122(3), 976-994.

Organic Trade Association, 2020. Organic industry survey 2020, available at: https:// www.ota.com/resources/organic-industry-survey (Accessed 26 November 2020).

Organic.org (2016). What is organic? Available at: http://www.organic.org/education/faqs (Accessed 24 July 2020). 
Pantano, E., Rese, A., \& Baier, D. (2017). Enhancing the online decision-making process by using augmented reality: A two country comparison of youth markets. Journal of Retailing and Consumer Services, 38, 81-95.

Park, C. W., Feick, L., \& Mothersbaugh, D. L. (1992). Consumer knowledge assessment: How product experience and knowledge of brands, attributes, and features affects what we think we know. ACR North American Advances, 19(1), 193-197.

Podsakoff, P. M., MacKenzie, S. B., \& Podsakoff, N. P. (2012). Sources of method bias in social science research and recommendations on how to control it. Annual Review of Psychology, 63, 539-569.

Podsakoff, P. M., MacKenzie, S. B., Lee, J. Y., \& Podsakoff, N. P. (2003). Common method biases in behavioral research: A critical review of the literature and recommended remedies. Journal of Applied Psychology, 88(5), 879-903.

Prakash, G., Choudhary, S., Kumar, A., Garza-Reyes, J. A., Khan, S. A. R., \& Panda, T. K. (2019). Do altruistic and egoistic values influence consumers' attitudes and purchase intentions towards eco-friendly packaged products? An empirical investigation. Journal of Retailing and Consumer Services, 50, 163-169.

Prakash, G., \& Pathak, P. (2017). Intention to buy eco-friendly packaged products among young consumers of India: A study on developing nation. Journal of Cleaner Production, 141, 385-393.

Rasoolimanesh, S.M., Roldán, J.L., Jaafar, M. \& Ramayah, T. (2017). Factors influencing residents' perceptions toward tourism development: Differences across rural and urban world heritage sites. Journal of Travel Research, 56(6), 760-775.

Rea, L. M., \& Parker, R. A. (2014). Designing and conducting survey research: A comprehensive guide. San Francisco (CA): John Wiley \& Sons.

Reingen, P. H. (1982). Test of a list procedure for inducing compliance with a request to donate money. Journal of Applied Psychology, 67(1), 110.

Reuters (2019). Natural and Organic Personal Care Products Market 2019 Global Industry Growth, Demand, Trend, Business-Opportunities, Applications \& Future Forecast Research Report by 2024. Available at: https://www.reuters.com/brandfeatures/venture-capital/article?id=85037 (Accessed 25 July 2020).

Rialti, R., Zollo, L., Pellegrini, M. M., \& Ciappei, C. (2017). Exploring the antecedents of brand loyalty and electronic word of mouth in social-media-based brand communities: do gender differences matter?. Journal of Global Marketing, 30(3), 147-160.

Rialti, R., Caliandro, A., Zollo, L., \& Ciappei, C. (2018). Co-creation experiences in social media brand communities. Spanish Journal of Marketing-ESIC, 22(2), 122141.

Rogelberg, S. \& Stanton, J. (2007). Understanding and dealing with organisational survey non-response. Organizational Research Methods, 10(2), 195-209. 
Roy, S.K., Balaji, M.S., Soutar, G., \& Jiang, Y. (2020). The antecedents and consequences of value co-creation behaviors in a hotel setting: a two-country study. Cornell Hospitality Quarterly, 61(3), 353-368.

Sadiq, M., Adil, M., \& Paul, J. (2020). An innovation resistance theory perspective on purchase of eco-friendly cosmetics. Journal of Retailing and Consumer Services. DOI: $10.1016 /$ j.jretconser.2020.102369.

See-To, E.W.K \& Ho, K.K.W. (2014). Value co-creation and purchase intention in social network sites: the role of electronic word-of-mouth and trust - a theoretical analysis. Computers in Human Behavior, 31(1), 182-189.

The World Bank (2020). International Monetary Fund World Economic Outlook 2019. Available at: https://data.worldbank.org/indicator/NY.GDP.PCAP.CD (Accessed 25 July 2020).

Vermeir, I., \& Verbeke, W. (2008). Sustainable food consumption among young adults in Belgium: Theory of planned behaviour and the role of confidence and values. Ecological Economics, 64(3), 542-553.

Wang, X., Yu, C., \& Wei, Y. (2012). Social media peer communication and impacts on purchase intentions: a consumer socialisation framework. Journal of Interactive Marketing, 26(4), 198-208.

Watts, S.A., \& Zhang, W. (2008). Capitalizing on content: Information adoption in two online communities. Journal of the Association for Information Systems, 9(2), 7394.

Xie, B., Wang, L., Yang, H., Wang, Y., Zhang, M. (2015). Consumer perceptions and attitudes of organic food products in Eastern China. British Food Journal, 117(3), $1105-1121$.

Yadav, R. (2016). Altruistic or egoistic: Which value promotes organic food consumption among young consumers? A study in the context of a developing nation. Journal of Retailing and Consumer Services, 33, 92-97.

Yang, T. (2012). The decision behavior of Facebook users. Journal of Computer Information Systems, 52(3), 50-59.

Yang, D., Jin, L., \& Sheng, S. (2017). The effect of knowledge breadth and depth on new product performance. International Journal of Market Research, 59, 517-536.

Zollo, L., Yoon, S., Rialti, R., \& Ciappei, C. (2018). Ethical consumption and consumers' decision making: the role of moral intuition. Management Decision, 56(3), 692710.

Zollo, L. (2020). The consumers' emotional dog learns to persuade its rational tail: Toward a social intuitionist framework of ethical consumption. Journal of Business Ethics. DOI: 10.1007/s10551-019-04420-4.

Zollo, L., Filieri, R., Rialti, R., \& Yoon, S. (2020). Unpacking the relationship between social media marketing and brand equity: The mediating role of consumers' benefits and experience. Journal of Business Research, 117, 256-267. 